time the catheter is in the patient's urinary tract system. Silver alloy catheters may not be cost-effective if used by patients who are catheterized only for short term.

Another example of an evenly distributed response is to the statement, "Everything in the room of a patient placed on Isolation Precautions should be considered contaminated and should be discarded or disinfected when the patient is discharged." If this statement is true, everything from all patient rooms (isolation or non-isolation) should be considered contaminated and should be discarded or disinfected when the patient is discharged, because there is no evidence that patients on isolation consistently shed more organisms than patients not on isolation. If this statement is not true, different criteria should apply for patient-care items, such as those that are likely to be soiled and those that are likely to be touched just before contact with a patient's mucous membranes or nonintact skin. The CDC's position on this controversy is stated in the "Guideline for Isolation Precautions in Hospitals" as stated below, ${ }^{12}$

Contaminated, reusable critical medical devices or patient-care equipment (ie, equipment that enters normally sterile tissue or through which blood flows) or semicritical medical devices or patient-care equipment (ie, equipment that touches mucous membranes) are sterilized and disinfected (reprocessed) after use to reduce the risk of transmission of microorganisms to other patients; the type of reprocessing is determined by the article and its intended use, the manufacturer's recommendations, hospital policy, and any applicable guidelines or regulations. Noncritical equipment (ie, equipment that touches intact skin) contaminated with blood, body fluids, secretions, or excretions is cleaned and disinfected after use, according to hospital policy. Contaminated disposable (single-use) patient-care equipment is handled and transported in a manner that reduces the risk of transmission of microorganisms and decreases environmental contamination in the hospital; the equipment is disposed of according to hospital policy and applicable regulations. ${ }^{12}$

The CDC has developed evidence-based guidelines for prevention and control of nosocomial infections since the early 1980s. Therefore, it is surprising that many of the respondents still believe in some of the dogmas not based on evidence, such as daily perineal care reducing the risk of catheter-associated urinary tract infections or protective isolation being an effective method to reduce risk of crossinfection to immunocompromised patients. This suggests that old dogmas die hard and old habits are hard to break.

This is the first evaluation of perceptions of infection control practices or dogmas of participants in a conference on healthcare-associated infections and provides a good baseline of infection control professionals' perceptions of various infection control practices. This can be beneficial in planning for education and research priorities on infection control and prevention. Efforts need to be made to clarify which dogmas have evidence of their efficacy or non-efficacy, as we educate infection control professionals to prevent healthcare-associated infection in the most costbeneficial fashion.

\section{REFERENCES}

1. Manangan LP. The infection control information system of the Hospital Infections Program, Centers for Disease Control. Am J Infect Control $1996 ; 24: 463-467$.

2. Lynch P, Cummings MJ, Roberts PL, Herriott MJ, Yates B, Stamm WE. Implementing and evaluating a system of generic infection precautions: body substance isolation. Am I Infect Control 1990;18:1-12.

3. Weinstein SA, Gantz NM, Pelletier C, Hibert D. Bacterial surface contamination of patient's linen: Isolation Precautions versus standard care. Am J Infect Control 1989;17:264-267.

4. Nauseef WM, Maki DG. A study of the value of simple protective isolation in patients with granulocytopenia. $N$ Engl J Med 1981;304:448-453.

5. Rego A, Roley L. In-use barrier integrity of gloves: latex and nitrile superior to vinyl. Am J Infect Control 1999;27:405-410.

6. Tablan OC, Anderson LJ, Arden NH, Breiman RF, Butler JC, McNeil MM. Guideline for prevention of nosocomial pneumonia. The Hospital Infection Control Practices Advisory Committee, Centers for Disease Control and Prevention. Infect Control and Hosp Epidemiol 1994;15:587-627.

7. Pearson ML, Hospital Infection Control Practices Advisory Committee. Guideline for prevention of intravascular device-related infections. Infect Control Hosp Epidemiol 1996;17:438-473.

8. Lai KK. Prolonging peripheral cannula and intravenous tubing use from 72 to 96 hours. Am J Infect Control 1998;26:66-70.

9. Smith I, Hathaway M, Goldman C, $\mathrm{Ng} \mathrm{J,} \mathrm{Brunton} \mathrm{J,} \mathrm{Simor} \mathrm{AE.} \mathrm{A} \mathrm{ran-}$ domized study to determine complications associated with duration of insertion of heparin locks. Res Nurs Health 1990;13:367-373.

10. Fink JB, Krause SA, Barrett L, Schaaff D, Alex CG. Extending ventilator circuit change interval beyond 2 days reduces the likelihood of ventilatorassociated pneumonia. Chest 1998;113:405-411.

11. Saint S, Elmore JG, Sullivan SD, Emerson SS, Koepsell TD. The efficacy of silver alloy-coated urinary catheters in prevention of urinary tract infection: a meta-analysis. Am J Med 1998;105:236-241.

12. Garner JS, the Hospital Infection Control Practices Advisory Committee. Guideline for isolation precautions in hospitals. Infect Control Hosp Epidemiol 1996;17:53-80.

\title{
Hospital-Acquired Malaria Transmitted by Contaminated Gloves
}

\section{Gina Pugliese, RN, MS Martin S. Favero, PhD}

Piro and colleagues recently described two cases of malaria occurring in a malaria-free zone in two in-patients, 2 weeks after a case of Plasmodium falciparum malaria, acquired in Burkina Faso, had been admitted to the same ward. After reviewing the techniques used by nursing staff, they concluded that transmission probably occurred via gloves contaminated following manipulation of venous cannulae and drip lines of the patient with Burkina Faso-acquired malaria, which were not discarded before manipulating the intravenous lines of the other two patients.

The authors suggest that nosocomial transmission of unusual and potentially lifethreatening infections should be taken into consideration in those settings where compliance with Universal Precautions is not rigorous.

FROM: Piro S, Sammud M, Badi S, Al Ssabi L. Hospital-acquired malaria transmitted by contaminated gloves. $J$ Hosp Infect 2001;47:156-158. 